\title{
Debranding in Fantasy Realms: Perceived Marketing Opportunities within the Virtual World
}

\author{
Kear Andrew, Bown Gerald Robin, Christidi Sofia. \\ Faculty of Business, Management, Accounting and Law. \\ University of Gloucestershire, Gloucestershire, UK
}

\begin{abstract}
This paper discusses the application of the concept of debranding within immersive virtual environments. In particular the issue of the media richness and vividness of experience is considered in these experience realms that may not be conducive to traditional branding invasive strategies. Brand equity is generally seen to be the desired outcome of branding strategies and the authors suggest that unless the virtual domains are considered as sacred spaces then brand equity may be compromised. The application of the above concepts is applied to the differing social spaces that operate within the different experience realms. The ideas of resonance, presence and interactivity are considered here. They lead to the development of a constructed positioning by the participants. Through the process of debranding, marketers may be able to enter these sacred spaces without negative impact to the brand. Perception of these virtual spaces was found to be partially congruent with this approach to branding. It thus presents a number of challenges for the owners of such virtual spaces and also virtual worlds in increasing the commercial utilization of investment in these environments.
\end{abstract}

Keywords-component; Fantasy Realms, Debranding; Sacred Space;Marketing; 3D Virtual Worlds; Second Life

\section{INTRODUCTION (MARKETING OPPORTUNITY IN FANTASY REALMS)}

The core focus of this paper is to assess the perceptions of opportunities within immersive virtual environments (IVEs). The particular environments discussed are the Fantasy realms within Second Life. The entrants to these fantasy realms develop a community of participation. Marketing opportunity is contingent upon the perception and selection of the optimum locations and channels to communicate with potential customers. It is therefore an outcome of perceived relevance of the selected locations to the brands being sold. There has been no qualitative research that explores the perceived relevance of fantasy realms to marketing. Therefore this research aims to establish, through exploratory qualitative research, the perception of these locations in terms of constructed positioning. It asks if fantasy realms within immersive virtual environments (IVE's) are sacred space within which no marketing activity is possible without negative reactions and brand resistance taking place. As such the core contribution of this research is that through exploring perceptions of a number of fantasy realms within Second Life (SL), the literature on virtual environments, branding, and debranding, the nature of opportunity can be gauged.

\section{BRANDING AND SOCIAL MEDIA}

A key consideration was suggested by Ref. [15] regarding the rapid deployment of branding activity into social media and online communities as marketers are becoming confronted with the stark realization that social media was made for people, not for brands. The development of these IVEs has developed to a stage where they can realistically be called Virtual Worlds where the immersion and interaction develop in a world of their own. The authors further suggest that for brands to gain coveted resonance, the brand must relinquish control [15]. A further consideration for branding was proposed [25] that suggested that whilst branding aims to influence the complex social conditions for branding due to successful branding relying on patterns of social interaction that are not only beyond the control of brand managers, but cites the autonomy of such patterns of social interaction that are crucial to the authenticity of the brand. He further suggests that thinking in terms of place branding reveals attempts to force the brand on local actors [25]. According to Ref. [51] which suggests that the misuse of social networking sites may be defined as failure to engage sincerely. However, the current extent of any misuse in Immersive Virtual Social Environments is unclear.

Research into Perceived Relevance and Value of Advertising in Online Communities found that if online networking communities want to achieve positive member responses to advertising, they should consider two key perceptual factors that have pivotal effects on behavioral responses: perceived relevance and value of community advertising [45]. Specifically, when users perceive community advertising as more relevant to the theme of community and thus more congruent to the extension of their social identities, they regard that advertising as more valuable and exhibit more positive behavioral responses to it.' Ref. [52] suggest that 'Online social networking communities are digital networks in which users feel an intrinsic connection to other members.

According to Ref. [1] consumers typically utilise and transform mythic and symbolic resources within the marketplace to construct narratives of identities enriched with symbolic meanings. In this way the particpants develop a community. However, research suggests that some consumers define their identities through an ongoing opposition to cultural and lifestyle norms [1].

Groups, or communities, of such consumers may become more of a liability to the communication of mythic and symbolic brands and as such erode brand equity. Consumer 
ideologies of resistance may result in the questioning of corporate interests and motives of such brand communications. The framing of such a perspective may be through the creation of lifestyles and identities that 'defy consumerist norms' [1] and offer identification for a subject based upon belonging, triggered by available signs and representations within perceived spatial volatility that expresses direct experiences of identity [25].

Ref [21] suggested that in this area 'identity formation as a process is spatially situated and thus one that is about creating symbolic spaces [21]. Whereby previous research has focused upon the anti brand movement [14] and consumer resistance and creativity [21], this research focuses upon the potential for brand resistance in immersive virtual environments such as Second Life. The perspective that all IVEs share the same views of resistance to commercial activities and exploitations in the market place of the real world may be too simplistic. However resistance to consumerist culture in some immersive virtual environments may share greater similarity to Ref. [12] work on resistance to consumer culture by lovers of the natural world. This may prove fruitful due to the type of experience realms [4] that exist in immersive virtual environments (IVEs) that may be better classified as 'sacred space'. The 4th Strand social network [8] of Second life may provide an increasing number of implications for brand communications to be carefully executed.

One of the key elements in the interactive space of the virtual worlds is the lack of materiality; their virtuality. It has been argued that the materiality of interaction is a factor that has been neglected in the understanding of markets [46]. This direct material engagement with products is absent during the interaction that occurs in the virtual world. The virtual nature of this world tends to bring forward the phenomenological aspects of marketing and the development of intentional objects [50]. It will however important to consider the virtuality together with the construction of such worlds. In this situation where the consumer engagement through possesion of branded goods is unavailable the process of brand building process needs to be reconceptulized.

\section{BRANDING AND BRAND EQUITY}

According to Ref. [44] building brands involves a number of elements that includes product attributes - that are intrinsic distinguishing and non-distinguishing elements - and the non product 'brand' attributes that are intangible extrinsic elements [10]. It is these intangible extrinsic symbolic elements such as the logo, brand, trademark etc that underpin the basic contributor to developing associations to the brand and build recognition and awareness. As such it is these fundamental elements that are the focus of this paper. Branding, importantly, aims to balance social forces with communication strategies according to Ref. [36] but however often fails to recognize the potential and challenges of these social forces [25] Brand management can be conceptualized as the utilization or creation of space for the interaction of actors within social and cultural norms that is outside the brand owner organization that reduces the opportunity for resistance [25]. This is with a desired outcome of building brand equity.
Brand equity is defined as "the added value with which a brand endows a product" [41]. According to Ref. [29] brand equity lies in the opportunity space between three important components; value proposition, brand name (awareness) and product or service experience. Ref. [50] argues that 'there are four dimensions of brand equity are brand awareness, brand associations, perceived quality, and brand loyalty'. It has been accepted for some time that brand awareness is one of best predictors of purchase' [2].

Brand differentiation as "a clear performance differential over competition on factors that are important to the target customers" [29], is essential in being able to support premium pricing and creating a positive brand influence on buying behaviour [34]. For instance involving a Second Life island for a brand could help to build a brand community and enhance brand differentiation and image through professionalism and creativity. Internet practitioners consider brand equity important [27], however through technological enhancements the brand equity model needs to be developed to incorporate these developments in IVEs. The web equity framework by Ref. [41] is rooted in the original brand equity model, but involving dimensions of web awareness and web image that are defined as the consumer familiarity and perceptions about a Web site. Others incorporate this idea of community together with interactivity and value [47]. These models are very useful in aiding and building relationships, however there are limitations of in-depth detail to the resonance level, consequently it is difficult for the concept to create value to the consumer [42] and new media and technology information such as the virtual platforms are not integrated into the models.

The branding literature suggests explicitly how branding takes place in controlled spaces such as Nike towns, Prada boutiques or Starbucks coffee shops but offers little explanation of how branding influences or fails to influence outside these controlled spaces [25].

\section{IMMERSIVE VIRTUAL ENVIRONMENTS}

Virtual worlds operate via Immersive virtual environment technology (IVET) allowing a consumer to feel more at one with his/her surroundings increasing the level of resonance felt. It has been identified that immersion in an IVE heightens the perceptive experience of individuals [3] [31].

The success of Virtual worlds is due in part to this sensation and occurrence of immersion. Ref. [5] suggests that full immersion can be likened to an altered state of consciousness claiming that you can daydream in a virtual world without leaving it. They present rich layers of synthesized sensory cues to the user so that they feel enclosed by the mediated environment and are willing to believe that the environment is real [52]. Virtual environments are technologically synthesized sensory information that makes the environment and their contents seem real [6]. The challenge lies in understanding the culture of virtual worlds and firms have to understand that this is the solution for being successful in these days: "If you love it, let it go." [7].

Second Life was founded to target adults for socializing, however marketers have found many opportunities to enhance brand equity and differentiation to enhance loyalty within this 
virtual platform. Traditional channels for marketing are less noticed by consumers [9] as barriers have been reduced by new techniques and technologies, therefore brands have had to find new mediums to grab the attention, interact and build relationships with consumers, with the immersion into virtual worlds has been shown to aid in this situation.

Second Life residents visit this virtual world almost as if it were a real place, exploring what others have created, meeting other residents, socializing, exploring intimacy and love, participating in individual and group activities, and buying items (virtual property) and services from one another [39].

The virtual world 'Second Life' allows the user to express their imagination in teleporting to a wide array of fantasy islands. It offers a sense of escapism whilst remaining life like. There is considered to be a greater role for imagination in these IVE's [11]. 'Avatars lifelike behaviours can make a site more engaging and motivating, making customer interaction with the website much smoother' [35]. Imaginative realms often need the protean nature of avatars. The relationship of play and construction is important in this virtual world. So these IVEs become life like although the separation from the real world is always acknowledged at a residual level. There is a constructed form of escapism and play. In a discussion of the form of play connected with the plastic arts [26] sees very little play in this art form. The static nature of this art can be compared with the performing arts and their construction of a play-sphere. Activity in these arts is often one of rapture and immersion. When considering the plastic arts such as sculpture, it is noted that 'where there is no visible action there can be no play' [26]. While there is a role for decoration and ritual in the engagement with the plastic arts what seems to be new here is that the plastic construction of virtual space requires immersive action with which to engage with it. So compared to traditional media, virtual environments better engage consumers and reproduce the real use experience [17], offering superior control and tailoring of messages [48].

In a realization of this role the focus of advertising in virtual environments is around interactivity and presence. Interactivity refers to a characteristic of a medium in which the user can influence the form and or content of the mediated experience [19]. The argument developed in this paper is that the concepts of presence and interactivity have a centrality in second life that relate to being positioned in the virtual space. Further developing this idea it can be seen that the form of constructed positioning is one that is particularly characteristic of second life. The software is designed to create an available space for interactivity. This interactivity is different in form that is generated from other technical environments such as websites and social media. The particular process of interactivity developed in this IVE depends on the requisitioning of the objects present in this virtual domain. We requisition them in order to make use of them; we interact with the other avatars that are present in the same virtual space. This interaction is generally with the objects that are virtual people. These avatars can be said to be requisitioned in a manner that relies on co-creation. The adoption of them in their interactivity requires greater immersive aspects than is the case in 'realworld' interaction. More specifically the immersive aspects are placed in the foreground to a greater extent by the assemblage created by this environment. These encounters with virtual objects require the process of selection from the created environment. This created environment can be seen as the standing reserve [18] the things from which we make a selection. The objects are called forward from the reserve in this way. This activity of making available can be seen as a crucial activity in Second Life; engaging in these activities provides the vitality and the interaction in the virtual world.

In what way does branding affect this calling-forward. In one way the brand communication provides ready recognition of those objects in the virtual world that are branded. The intention of branding in the literature is complex, its purpose is either to provide meaning [27] or, revealed in a discussion of corporate branding, to provide image [13]. Through both of these elements it can be said to promote connection or recognition in a potentially strange world. The branding by its very nature calls itself forward and demands availability. As branding is maintained over time there have been various strategies adopted towards branding in the virtual space.

\section{DOMAINS OF INTEREST AND EXPERIENCE REALMS}

Much psychology and social-psychology supports the notion that people select their domains of interest based upon their values. As such many domains of interest exist from Art to Extreme sports and painting to snowboarding. In addition to which there are many domains such as sports, technology, travel, and fashion etc whereby those with congruent values select to spend their time engaging with others with similar values.

It is these domains that offer an opportunity for building brand equity through debranding in order to ensure non invasive exposure that does not compromise the overall experience of those immersed in the virtual environment.

This discussion question is assuming increasing importance. Virtual usage by firms and customers is increasing year by year [39]. In $2010 \$ 1.6$ billion was spent by Americans to buy virtual goods for Avatars in virtual worlds [11]. Whilst accepting this trend others imply that virtual worlds are a fad and therefore perception of marketing opportunity may be limited [47]. More organizations are finding the shared value [44] and potential [50] of having a presence in online communities to sell products, provide a service or accommodate events [20] as they aid in building brand equity, brand revitalization, and increasing commitment and loyalty. This is likely to result in greater consumer repeat purchases, more consumer information and positive word-of-mouth (WOM). In fact the WOM effects can mitigate the negative effects of advertising in online communities. This suggests that the idea of interaction is powerful in this context. [31]. In addition virtual communities allow for stronger relationship ties as they give the members a sense of attachment and purpose [44] as well as "meeting social and psychological needs that can be categorized as follows: information, relationship building, social identity/self-expression, helping others, enjoyment, status/influence and belonging". This can be an advantage for marketers as their avatar within the community can act as an advocate influencing consumers' opinions and behaviours [32] and [38]. 
Ref. [4] divided the experience realms that can be found in the virtual world environment into the following 4 categories:

1) Entertainment (passive absorbed). In a virtual world, this would include the consumption of media content, or of live content, such as viewing a stage performance in the virtual world, watching a movie on a screen in SL or listening to music or radio.

2) Education (active absorbed). Various examples in a virtual world environment include tutorials and online lectures. There are many examples of universities and other organizations that are now using Second Life for educational and teaching purposes.

3) Escapist (active immersion). For example, casinos, themed areas and 'sims' (i.e., 3-D virtual games within SL) all provide this kind of escapism. An example of a 'sim' would be a virtual world area with a gothic theme or a science fiction combat theme.

4) Esthetic (passive immersion). A typical virtual world example would be visiting a museum in SL such as the Second Life International Space Museum, Second Louvre or the Open Art Museum.

5) Sacred Space. A socially meaningful space which is based on engagements beyond that of consuming. For example rich social spaces to escape the real world such as virtual islands, parks, etc

Ref.[4] categories of experience realms does not explicitly suggest that overlaps may exist such that an escapist realm may also have esthetic qualities and immersion implications of both a passive and active nature. In essence they suggest that there are clear delineations between the types of realms. There may also be the implication that an organization seeking to create superior brand equity for competitive advantage would enter any of the first four realms above better than its competitors. For example, an education institution looking to offer students a better experience of learning through Second Life must do so by making this experience more absorbing and through utilizing some of the strengths of other realms make it actively immersive. The authors herein recognize that the above experience realms are a very useful starting point and with the addition of an experience realm to cater for spaces where negative brand perceptions are likely such as Sacred spaces. This certainly adds value in highlighting some potential brand issues for marketers. The experience realm of sacred space (5) may be added to guide marketers in their brand communications so as not to erode equity. The characteristic of such space may be rich in cultural values and perceptions that possibly distort or work against the brands identity.

In virtual reality many different types and combinations of experience realms are likely to exist with a variety of levels of brand interaction and it is through examination of these that one may be able to determine the receptivity towards brand exposure. A key question that emerges in relation to this research is what constitutes Sacred Space? And does it actually exist within virtual immersive environments? These are the focus of this paper.

\section{SOCIAL BENEFITS, LIABILITIES AND THE ROLE OF DEBRANDING}

Some of the successes of social networks are based on the principles of replicating the experience of the 'real world'. However there are also many examples of social networks bashing brands as a result of their invasive techniques.

Previous work has studied individual and communities resisting market logic. Examples from the offline world include festival goers aiming to exist - even momentarily- outside of previously established commercial structures [34]. There are well documented consumer accounts exhibiting anti-brand attitudes [24]. Taking this to the online realm, anti-brand communities have been identified to form against specific brands and to gain social benefits by collectively pulling together in their commercial opposition towards these social network dynamics [23]. Brands have also been found to participate as 'uninvited' and to cause commercial reactions when deciding to enter primarily consumer led online spaces such as social media and video sharing websites [15]. Such anti-brand issues call into question the conditions under which commercial acts and branding might be acceptable within IVEs. We suggest that the process of debranding might be a relevant process to consider in terms of providing the grounds for such conditions.

Ref. [43] discussed 'debranding' as a no-name marketing strategy gaining acceptance in relation to branded products. In a more modern twist strongly established brands can be found to spatially debrand themselves in particular settings. Indicatively, instances of targeted elimination of the brand name is becoming a popular way for companies to differentiate themselves or extend their business in an effort to appear less corporate and more integrated with the social spaces and actors within them [37].

The range of organizations engaging in such activities is diverse: from Starbucks' '15th Ave Coffee \& Tea' shops, with only 'Inspired by Starbucks' on them [37] to zoo animals being sponsored by well known brands such as Nescafe, but with the brand logo font changed and carved on a wooden plaque to signify a more natural feel (Athens Zoo, Greece). Consumers have also been found to engage in related practices, for example car enthusiasts 'debadging' their cars and rearranging the letters of the brand name in a playful and personal fashion [22].

The issue of commercial fit with online user activities (such as online gaming and the presence of arousing commercial billboards as investigated by Ref. [16]) has been documented. Online debranding, through the adjustment or temporary removal of previously ascribed brand layers (such as Nescafe's reconfigured type font for a particular space), might provide the conditions for non invasive commercial practices and the immersion sought in IVEs.

One visits the Zoo to see animals and yet commercial branding results in various animals being commercially sponsored to capitalize on the opportunity to build awareness and equity. However one may consider the domain of animals in Zoo's as not fair game for capitalizing commercially on their situation by including brand logo's, names, fonts etc. As such 
this branding activity could be seen as somewhat invasive and compromising the brand equity. However when considering debranding (offering a transparent version of the logo or standard font for the brand name) the cues and connections between these brands may result in the brand becoming strengthened with a greater potential for building brand equity.

In the process of debranding or debadging many would suggest that Nike was the first, but now the practice of eliminating the brand name from products or marketing activity is becoming a popular way for companies to differentiate themselves or extend their business [37]. The debranding has often occurred in a situation of familiarity, and the playful nature of debranding often relies on previously established recognition. The counterintuitive nature of dropping a well-known company name or logo from a product or marketing activity, offers a debranding strategy to make their companies and brands appear less corporate and more forward-thinking [36] and less separate from the social spaces and actors within them.

\section{METHODOLOGY}

Exploratory qualitative research was undertaken with a cohort of 16 2nd year marketing students aged 19-22 who were selected as a result of their marketing knowledge regarding brands and branding and as they represent the future commercial marketing decision makers. They students were asked to explore a Second Life Fantasy Realm of their choosing. Then the students were interviewed to ascertain their views on the limitations and marketing opportunities that exist within that chosen realm. A total of 10 fantasy realms were explored.

\section{FINDINGS}

The fantasy realm locations selected by the research participants included, Winterfell x4, Dirty Talk Bar, Virtual Reality Project, Soul Sensation, Caribbean Resort, Eleven Caves Siden, the Doomed Ship x2, Java Island, Spuzikuzi, and Miami Beach.

A range of motives were perceived as the reasons why someone would visit the research participants chosen realms including; nostalgia $\mathrm{x} 2$, for adventure and fun, to see something different from the real world, looking for excitement and adventure, escapeism $\mathrm{x} 2$, visit somewhere you could not afford to go, relaxing, socializing, gain human interaction, exploring, couples experiences, for a beach experience, to find love, take part in sports, and enjoyment.

Those research participants that suggest that marketing would not be suitable for their chosen realm were for the following reasons;

The chosen realm was a Soul Sensation

"Too much commercialization would spoil the atmosphere" Emma.

The chosen realm of the Doomed ship

"You can't advertise using posters as it would ruin the environment" Evie.

The chosen realm was Java Island
"It is beautiful but not realistic. Due to the chilled out environment, I doubt that product placement would be valued in this realm" Maria.

The majority of research participants that suggest that marketing may be suitable was based on the following statements;

The chosen realm of Winterfell

"The buildings and realm as a whole is quite busy and full and if fully immersed they are likely to react positively to marketing that is blended in" Hannah.

"Maybe marketing would work in the houses i.e. sofa's etc so as not to conflict with the nature in Winterfell" Amanda.

"It is probably not relevant to contemporary / modern brands but old world brands may fit with the theme" Andrew

The chosen realm of the Doomed Ship

"Everything is dark and spooky - so you could play with the design as long as it fits in with the theme such as horror movies" Louisa.

The chosen realm was Soul Sensation

"Leisure products could be marketed that fit in with the beach theme" Jessica.

The chosen realm was Java Island

"The design might need to be boring - you could have avatar travel agents" Sadie.

The chosen realm was the Virtual Reality Project

"Lots of white space and a choice of quirky objects to pursue

- could be more immersive if you purchased something"

Robert.

The chosen realm was the Dirty Talk Bar

"A stylish bar - therefore themed cocktails might work" Chris. The chosen realm was the Caribbean Resort

"Any tourism holiday companies and water sports, pubs/clubs would work" James.

The chosen realm was Spuzikuzi

"You could have agents to chat to and to show off their art work" Janice.

\section{DISCUSSION: IVES: THE PRIMACY OF SACRED, YET COMMERCIALLY PERMEABLE, REALMS}

The findings relate to the issue of immersion in online environments [5]. A key theme emerging from the data is the primacy of the online setting and the secondary - and complementary- role of any potential commercial activity. The articulated perceived reasons for a user to visit these online sites exhibited no explicit commercial activity as a perceived driver. Furthermore, there was a commonality of drawing on the importance of relevance and of preserving the 'environment', the 'atmosphere' and the 'theme' of the online settings in the light of any prospective commercial activity.

In this sense, such online realms were viewed as the type of realm theorized by Ref. [4] as sacred spaces, realms with no primary market function and of a social value ('for socializing, 'to gain human interaction, 'for couples' experiences', 'to find love' in our informant's words). Yet, although sacred to commercialization to a degree, they were still perceived as potentially permeable and open to marketing and branding activities under certain conditions. Such conditions, as explained above, were viewed around the need to follow the 
already established realm character, and resonate with it. They were also related to the concept of segregating spaces and finding permeable commercial spaces within the wider sacred realm: as noted for example branding activity could be kept within the materially based houses rather than in the wider natural realm (Winterfell).

\section{CONCLUSIONS AND IMPLICATIONS FOR BRAND MANAGEMENT IN FANTASY REALMS}

The outcome of this conceptual paper involves the concept of relevance. Relevance is a key concept to consider in addition to differentiation. The Young and Rubicam brand asset valuator considers relevance to be an important concept in a brands future financial performance [40]. Whilst its application was largely derived for the physical and real world the concept of relevance may offer significant value in exploring different experience realms within the virtual world. The idea of relevance must be connected to the vituality of such IVEs and the idea of the 'standing reserve' of availability that provides the interactive experience. The need to engage and effectively communicate with potential customers may provide a juxtaposition of eroding brand perceptions if traditionally applied to the context of experience realms. In addition avoiding particular experience realms that may offer little relevance and availability limits the potential exposure. As such exploring these realms for what they mean and adapting the core brand through debadging may facilitate brand exposure in otherwise taboo sacred realms.

'The issue of brand building in virtual worlds is embryonic... It is likely to follow a similar learning curve to other new media, such as the Web and mobile telephony' [4]. The question becomes - is it going to be business as usual for brand development in virtual worlds?

The implications for building a brand presence that is not invasive within the realms of sacred space and brand communities, that helps to increase brand equity stems from the concept of debranding explored within this paper. Although there may be limited branding opportunity for utilizing non congruent sacred spaces and the resultant visual cues and semiotic effect of the brand greatly lessened, if the reduction of cues takes place some additional exposure and resonance may take place. The sacrifice need not be a lack of a deep understanding of the brand. Where [53] suggests that organizations and brands run the risk of making themselves look separate by not interacting with the space and the audiences, is going against transparency and oneness, a minor reduction of brand cues may overcome this. There has been some discussion of the idea of calling forward the objects in the virtual realm that are available for our interaction. The idea of branding, in either developing awareness or promoting its relevance in this domain challenges the unique element of immersion and calling forward that is characteristic in this virtual world. The raison d'etre in the Immersive Virtual Environments is the experience. It is this experience which needs to be respected and a strategy that attempts to colonize the virtual world as part of an existing brand strategy is one that might not be appropriate but also runs the risk of failing to grasp the potentiality for these types of immersive environments

\section{FUTURE RESEARCH}

The aim of this exploratory paper was to establish to which degree fantasy realms could be viewed as sacred space. The current findings both conceptualize and pinpoint the marketing potential to enter such realms. Future work should aim to look closer at the conditions for acceptance in different realms where existing brands already operate and to establish the need and the suggested forms of debranding strategies.

\section{REFERENCES}

[1] Arnould, E. J., \& Thompson, C. J. (2005). Consumer Culture Theory (CCT): Twenty Years of Research. Journal of Consumer Research, 31(4), 868-882

[2] Axelrod, J. N. (1968), "Advertising Measures that Predict Purchase," Journal of Advertising Research, 8, 3-17

[3] Blascovich, J., \& Bailenson, J. N (2011, in press). Infinite Reality Avatars, Eternal Life, New Worlds, and the Dawn of the Virtual Revolution. New York: William Morrow.

[4] Barnes, S., Mattsson, J., 2008, Brand Value in virtual Worlds: An axiological approach, Journal of Electronic Commerce Research, Vol.9, No.3

[5] Bartle, R. (2003), Designing Virtual Worlds, New Riders, Indianapolis, IN.

[6] Blascovich, J., Loomis, J., Beall, A. C., Swinth, K. R., Hoyt, C. L., \& Bailenson, J. N. (2002). Immersive Virtual Environment Technology: Just Another Methodological Tool for Social Psychology? Psychological Inquiry, 13(2), 146-149.

[7] Burke, P.; Darras, D.; Gerenski, K.; Gordon, M. E. (2007): The Virtual Brand Footprint: The Marketing Opportunity in Second Life,

[8] Cachia R., Compano, R., Da Costa, O. 2007 Grasping the potential of online social networks for foresight, Technological Forecasting and Social Change, Vol.74. PP1179-1203

[9] Chaffey, D. and Smith, P.R. (2008), E-marketing Excellence: Planning and Optimizing your Digital Marketing, 3rd ed., ButterworthHeinemann, Amsterdam.

[10] Costa, R., Evangelista, S., (2008),"An AHP approach to assess brand intangible assets", Measuring Business Excellence, Vol. 12 No: 2 pp. 68-78

[11] Denegri-Knot, J., and Molesworth, M. (2010) 'Concepts and Practices of Digital Virtual Consumption', Consumption Markets and Culture Vol.13, No.2, pp109-132

[12] Dobsha, S., 1998, The lived experience of consumer rebellion against marketing, In Alba, J.W., \& Hutchinson(eds), Advances in Consumer Research, Vol.25, pp91-97, Provo, UT.

[13] Fetscherin, M., \& Usunier, J. (2012). Corporate branding: an interdisciplinary literature review. European Journal of Marketing, 46(5), 733-753

[14] Fischer, E. (2001). Rhetorics of Resistance, Discourses of Discontent. Advances In Consumer Research, 28(1), 123-124

[15] Fournier, S., Avery, J.(2011) Business Horizons, May, Vol. 54 Issue: Number 3 p193-207, 15p

[16] Greengard, S. (2011). Social games, virtual goods. Association for Computing Machinery: Communications of the ACM, Vol. 54 (4), 19.

[17] Grigorovici, Dan (2003), "Persuasive Effects of Presence in Immersive Virtual Environments," in Being There: Concepts, Effects and Measurements of User Presence in Synthetic Environments, Giuseppe Riva, Fabrizio Davide, and Wijnand A. Ijsselsteijn, eds., Amsterdam: IOS Press, 191-207,

[18] Heidegger, M., 2012, Bremen \& Freiburg Lectures, Indiana University Press, Bloomington

[19] Heeter, C. (2000), "Interactivity in the context of designed experiences", Journal of Interactive Advertising, Vol. 1 No. 1,

[20] Hemp, P. (2006), “Avatar-based marketing", Harvard Business Review, June, pp. 48-57. 
[21] Hetherington, K. (1998) Expressions of Identity: Space, Performance, Politics London, Thousand Oaks Ca., New Delhi: Sage/Theory, Culture and Society

[22] Hewer, P., \& Brownlie, D. (2010). On market forces and adjustments: acknowledging consumer creativity through the aesthetics of 'debadging'. Journal Of Marketing Management, 26(5/6), 428-440

[23] Hollenbeck, C. R., \& Zinkhan, G. M. (2006). Consumer activism on the internet: the role of anti-brand communities. Advances in Consumer Research, 33, 479.

[24] Holt, D. B. (2002). Why do brands cause trouble? A dialectical theory of consumer culture and branding. Journal of consumer research, 29(1), 7090.

[25] Hornskov, S.B. (2007) On the management of authenticity: Culture in the place branding of Oresund., Place Branding and Public Diplomacy. Vo.3. No.4, pp317-331

[26] Huizinga, J. (1949) Homo Ludens: A study of the play-element in culture. Routledge and Kegan Paul, London

[27] Jevons, C., Abbott, M., \& de Chernatony, L. (2005). Customer and brand manager perspectives on brand relationships: a conceptual framework. Journal of Product \& Brand Management, 14(5), 300-309.

[28] Jobber, D. and Fahy, J. (2006), Foundations of Marketing, 2nd ed., McGraw Hill, New York, NY.

[29] Kapferer, Jean-Noël (2004), The New Strategic Brand Management: Creating and Sustaining Brand Equity Long Term, (Third ed.), London: Kogan Page.

[30] Keeling, K.A., P.J. McGoldrick, and S. Beatty. 2007. 'Virtual Onscreen Assistants: A Viable Strategy to Support Online Customer Relationship Building?' Advances in Consumer Research 34: 138-144.

[31] Keng,C-J., Ting,H-Y., Chen,Y-T., 2011, Effects of virtual-experience combinations on consumer-related "sense of virtual community, Internet Research, Vol. 21 Iss: 4 pp. 408 - 434

[32] Kim, J., Chio, J., Qualls, W. and Han, K. (2008), 'It Takes a Marketplace Community to Raise Brand Commitment: The Role of Online Communities', Journal of Marketing Management, 24(3-4), pp. 409-431.

[33] Kozinets, R. V. (2002). Can consumers escape the market? Emancipatory illuminations from burning man. Journal of Consumer Research, 29(1), 20-38.

[34] Kuhn, K.-A.L., Alpert, F. \& Pope, N.K.L., 2008. An application of Keller's brand equity model in a B2B context. Qualitative Market Research: An International Journal, 11(1), pp.40-58.

[35] Luo, J.T. McGoldrick, P., Beatty, S., Keeling, K.A., (2006) "On-screen characters: their design and influence on consumer trust", Journal of Services Marketing, Vol. 20 Iss: 2, pp.112 - 124

[36] Lury, C. (2004) 'Brands: The Logos of the Global Economy', Routledge, Oxon, NY

[37] MarketingWeek (2012)Debranding the Great Name Dropping Gamble, 5th April. Accessed online http://www.marketingweek.co.uk/trends/debranding-the-great-namedropping-gamble/4001018.article
[38] McGoldrick, P., Keeling, K. and Beatty, S. (2008), 'A Typology of Roles of Avatars in Online Retailing, Journal of Marketing Management, 24(3-4), pp. 433-461.

[39] Miano, T. J. ( 2007, August). Virtual World Taxation: Theories of Income. Retrieved March 2011, from Selected Work : http://works.bepress.com/cgi/viewcontent.cgi?.article=1000\&context=ti mothy_miano

[40] Mizik, N., \& Jacobson, R. (2008). The Financial Value Impact of Perceptual Brand Attributes. Journal Of Marketing Research (JMR), 45(1), 15-32.

[41] Page, C., Lepkowska-White, E, (2002) "Web equity: a framework for building consumer value in online companies", Journal of Consumer Marketing, Vol. 19 Iss: 3, pp.231 - 248

[42] Pappu, R., Quester, P.G. and Cooksey, R.W. (2005), "Consumer-based brand equity: improving the measurement empirical evidence", Journal of Product \& Brand Management, Vol. 14 No. 3, pp. 143-54.

[43] Parasuraman, A. (1983). "Debranding": A Product Strategy With Profit Potential. Journal of Business Strategy, 4(1), 82-87.

[44] Porter, M. E., \& Kramer, M. R. (2011). Creating shared value. Harvard Business Review, 89(1/2), 62-77

[45] Ridings, C. and Gefen, D. (2004), "Virtual Community Attraction: Why People Hang Out Online," Journal of Computer-Mediated Communication, 10 . 10 . August 29, 2008).

[46] Shove, E., Araujo, L., 2010, Consumption, materiality, and markets, in Reconnecting Marketing to Markets, OUP, Oxford.

[47] Solomon, M.R., Bamossy, G. J., Askegaard, S. T., and Hogg, M.K. (2013) Consumer Behaviour A European Perspective 5th Edition, Pearson, London

[48] Tam K.Y., Ho S.Y., (2006). Understanding the impact of web personalization on user information processing and decision outcomes. MIS Quarterly, 30(4), 865-890.

[49] Tikkanen,H., Hietanen, J., Henttonen,T., Rokka, J., (2009),"Exploring virtual worlds: success factors in virtual world marketing", Management Decision, Vol. 47 Iss: 8 pp. 1357 - 1381

[50] Washburn, J. H., Plank, R. E. (2002). Measuring Brand Equity: An Evaluation of A Consumer-Based Brand Equity Scale. Journal of Marketing Theory \& Practice, 10(1), 46.

[51] Wilson, A., (2012), What can phenomenology offer the consumer?: Marketing research as philosophical, method conceptual, Qualitative Market Research: An International Journal, Vol. 15 No.3 pp. 230 - 241

[52] Wellman, B and Gulia, M (1999), "Net-Surfers Don't Ride Alone: Virtual Communities as Communities," in Networks in the Global Village, B. Wellman, ed. Boulder, CO: Westview Press, pp 331-366.

[53] Witmer, B.G. Singer, M.J. (1998). Measuring Presence in Virtual Environments: A Presence Questionnaire. Presence, Vol. 7, No. 3, pp. $225-240$

[54] Yan, J. (2011) Social media in branding: fulfilling a need. Journal of Brand Management. Vol.18, No.9. pp688-696 